\title{
Smart irrigation of agricultural crops
}

\author{
Murodov Otabek Ulugbekovich ${ }^{1}$, Kattayev Bobir Sobirovich², Saylixanova Maftuna Komiljonovna², \\ Ibodov Islom Nizomiy o`g ${ }^{`} i^{2}$ \\ ${ }^{1}$ assistant of the Bukhara branch of the Tashkent Institute of Irrigation and Agricultural Mechanization Engineers. \\ ${ }^{2}$ student of the Bukhara branch of the Tashkent Institute of Irrigation and Agricultural Mechanization Engineers.
}

Abstract. This article provides an overview of the concept of "smart irrigation" and a review of the results of research conducted abroad on smart irrigation.

Keywords: smart irrigation, WFD device, WiFi rotor, irrigation duration, irrigation norms, filtration, pre-irrigation soil moisture.

\section{Introduction}

Today in the world agricultural practice there are many terms such as "Smart agriculture - smart agriculture", "Smart farming - smart farming", "Smart irrigation - smart irrigation" [2].

From 2017 to 2022, the expansion of automated systems and technologies for "smart agriculture" around the world is projected. In particular, VRT (variable speed technology) system and GPS receivers make a significant contribution to the growth of this network [1].

\section{The results}

So the question naturally arises, what is meant by "smart agriculture" or "smart farming"? (Figure 1). In this case, the full management of the farm provides for "decision-making systems", ie increasing revenue by optimizing costs by saving resources, GPS, GNSS (Global type) satellite imagery), mapping and monitoring of crop yields, organic matter, nitrogen and moisture content, soil salinity, water resources and other indicators using hyperspectral images. are planned systems of [2].
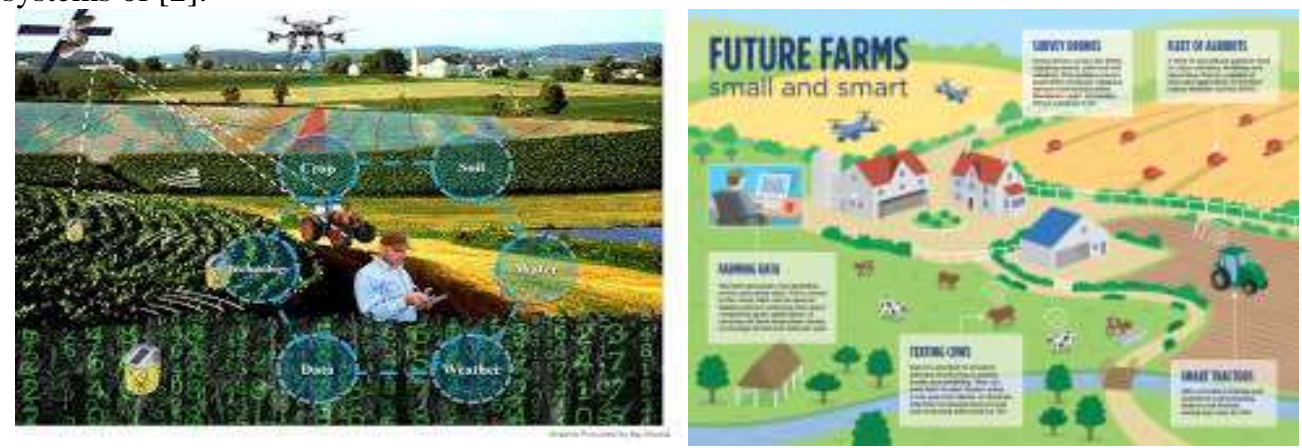

In the field of agriculture in foreign countries, "Smart irrigation - smart irrigation" is widely introduced in large areas in the United States. "Smart irrigation" means clear decision making in irrigation or intelligent management of irrigation. For example, using sensory moisture meters (TDR, Data Snap, WFD) and, in addition, information and communication devices (Web server, WiFi rotor), it is possible to determine the water demand of crops, make a clear decision on irrigation by monitoring soil moisture. This will increase revenues by optimizing costs by saving water resources and manpower.

In order to ensure the implementation of the Resolution of the President of the Republic of Uzbekistan "On measures to organize the activities of the Ministry of Water Resources of the Republic of Uzbekistan" dated April 17, 2018, the Cabinet of Ministers adopted a resolution on September 10, 2018. Measures have been taken to ensure the rational use of water resources, modern information technologies in irrigation of agricultural crops and The development and implementation of programs has been identified as an urgent task [3]. 
Based on the above urgent tasks, it will be possible to achieve water and resource savings and high yields in our country through the development of smart irrigation, ie automated control of information demand for crops using new modern sensory devices based on information technology and its implementation in agriculture and water management.

According to the Australian scientist R. Stirzaker, the WFD tool was developed to answer the question "What is the simplest information for swimmers to make better decisions" because the implementation of the developments developed by farms on irrigation schedules has been unsatisfactory [4].

In a study in Australia using the WFD tool, irrigation was carried out at intervals of 4 to 7 days with 4 WFD tools installed in a $15 \mathrm{~cm}$ layer of soil for the purpose of irrigating lawn grasses. At the same time, irrigation was stopped automatically with the help of 3 detectors to detect the presence of moisture in the specified soil layer. The accuracy of this method has been proven to be surprisingly high. Each irrigation indicated that the marked layer was almost completely moistened. In this case, it was proved that the soil in the $30-50 \mathrm{~cm}$ layer of the soil is dry and the lawn grass is not irrigated excessively, only the calculated layer of soil is moistened [5].

According to observations by PBCharlesworth, there are more than 20 views of soil moisture monitoring, among which the question of which is the most accurate and precise method can certainly be answered as a method of determining soil moisture using a WFD instrument. In Australia, studies to determine soil moisture levels in vegetable crops have compared the use of reflectometers (TDR), vetting front detectors (WFD), and tensiometers. According to the data obtained by measuring the humidity in the unit of volume, the moisture content in the $40 \mathrm{~cm}$ soil layer decreased by $19.6 \mathrm{~mm}$ in 2-4 days, and by $11.6 \mathrm{~mm}$ in 5-7 days, and the difference between them was $6.5-3.9 \mathrm{~mm}$ per day. found to be Similar results were found in the third irrigation cycle,

When comparing tensiometer and vetting front detector devices after irrigation in 20 and $40 \mathrm{~cm}$ layers, $92 \%$ of the installed vetting front detector in $20 \mathrm{~cm}$ layer was $<15 \mathrm{kPa}$, and $74 \%$ of the installed vetting front detector device at $15 \mathrm{kPa}$. was found to be active. When these values were analyzed over a $40 \mathrm{~cm}$ layer of soil, it was found that $95 \%$ of the vetting front detector was active when the tensiometer reading was $<7 \mathrm{kPa}$, and only $28 \%$ was active when the installed vetting front detector was $>7 \mathrm{kPa}$ [7].

RJStirzaker noted that the results of a study conducted by PAHutchinsons on the control of irrigation using a vetting front detector device when using sprinkler irrigation in field conditions showed that the interval of irrigation is one of the most important aspects in irrigation control [8].

A study by the International Water Resources Management Institute on the use of a vetting front detector to improve the use of irrigation water on small farms in Ethiopia found that a vetting front detector provides a basis for effective water use. It was found that the use of the Vetting front detector increased water efficiency by $9 \%$ and productivity by $13-17 \%$. The reduction in the number of irrigations when using this tool also leads to a reduction in the labor force (11 working days per hectare) [9].

According to Brazilian researchers, one of the key questions in irrigating arid areas is "when" and "how much". The data are aggregated into mathematical models and agro-recommendations are given to farms through evapotranspiration calculations. $\mathrm{n}[10]$.

\section{Conclusions}

In conclusion, the use of information technology-based smart irrigation using a new modern WFD tool in making clear and accurate decisions on irrigation will pave the way for achieving high yields and efficiencies. Bunda:

- It is advisable to install a total of 3 WFD devices at the beginning, middle and end of the field, where the average field uniformity is observed on farms, to monitor irrigation by installing a WiFi rotor device at the edge of the field and sending data to a computer program.

- With the use of smart irrigation, the optimal duration of irrigation of crops and when to stop watering are clearly defined, saving $10-15 \%$ of water resources.

\section{References}

[1] http://www.xabar.uz/uz/texnologiya/endi-qishloq-xojaligi

The system will be both smart

[2] Avliyoqulov M.A., Durdiev N.H. Smart irrigation of cotton // "IRRIGATION AND LAND RECLAMATION" magazine. - Tashkent, 2019. - №3 (17). - B. 13-21. 
[3] Resolution of the President of the Republic of Uzbekistan "On measures to increase the efficiency of water resources" dated July 2, 2018 No PP-3823. - Tashkent, 2018. - 8 p.

[4] Stirzaker, RJ (2003). When to turn the water off: scheduling micro-irrigation with a wetting front detector. Irrigation Science, 22 (3-4). Pp. 177-185.

[5] Hutchinson, PA, Stirzaker, RJ (2000) A new method and device for scheduling irrigation. Irrigation Association of Australia, May 23-25, 2000 National Conference. Pp. 584-592.

[6] Charlesworth, PB (2000). Irrigation Insights No 1 - Soil Moisture Monitoring. National Program for Irrigation Research and Development, CSIRO Publishing, Melbourne, Australia.

[7] Stirzaker, R., Etherington, R., Lu, P., Thomson, T., \& Wilkie, J. (2005). Improving irrigation with wetting front detectors. Pp. 1-68.

[8] Stirzaker, RJ, \& Hutchinson, PA (2006). Irrigation controlled by a wetting front detector: field evaluation under sprinkler irrigation. Soil Research, 43 (8), Pp. 935-943.

[9] Stirzaker, R., Stevens, J., Annandale, J., Maeko, T., Steyn, M., Mpandeli, S., Maurobane, W., Nkgapele, J. and Jovanovic, N., 2004. Building capacity in irrigation management with wetting front detectors. Water Research Commission.

[10] Carlesso, R., Petry, MT and Trois, C., 2008, October. The use of a meteorological station network to provide crop water requirement information for irrigation management. In International Conference on Computer and Computing Technologies in Agriculture (Pp. 19-27). Springer, Boston. 